\title{
'Roadmap to the Land of Adrenals' - A Comprehensive Guide to Master the Radiological Diagnosis of Adrenal Gland Lesions
}

\author{
Venkatesh Bala Raghu Raji1 ${ }^{1}$ Rajoo Ramachandran², Prithiviraj Periasamy Varadaraju³, \\ Prabhu Radhan Radhakrishnan ${ }^{4}$, Madhumalar Anbalagan ${ }^{5}$ \\ 1, 2, 3, 4, 5 Department of Radio Diagnosis, Sri Ramachandra Institute of Higher Education and Research, \\ Porur, Chennai, Tamil Nadu, India.
}

\section{ABSTRACT}

\section{BACKGROUND}

Adrenal glands are one of the commonest sites in humans to have incidentalomas. Majority of the lesions are picked up as incidental findings in abdominal CT and chest CT, which were originally indicated for different reasons. Lesions afflicting the adrenals can be benign, indeterminate, or malignant. Adrenal adenoma is the commonest lesion in the adrenal glands. Although it is easier to differentiate benign from malignant lesions, differentiating benign from indeterminate lesions and indeterminate lesions from malignant lesions requires skill and experience. It is important to differentiate them precisely with imaging modalities alone, in order to avoid unnecessary biopsies, as adrenal biopsies are known to cause inadvertent complications.

This is a retrospective study which was done for a period of 3 years from April 2015 to April 2018 using 1.5 T MRI and 64 slice CT. Among 2412 cases which came for evaluation, 145 patients were diagnosed to have adrenal lesions. These 145 cases were further stratified into benign and malignant lesions by various imaging features. The indeterminate adrenal lesions were correlated with histopathological analysis and immunohistochemical staining.

Although contrast enhanced MDCT is the gold standard in imaging the adrenal lesions, MRI is still indispensable in diagnosing indeterminate lesions. This article elaborates the imaging findings of common adrenal lesions and substantiates the critical differentiating features which the radiologists should be aware of, in order to differentiate the various benign lesions from the malignant ones. The importance of this differentiation lies in the fact that proper diagnosis obviates unwarranted adrenal biopsies.

\section{KEY WORDS}

Washout, Adenoma, Phaeochromocytoma, Adrenocortical Carcinoma, Incidentaloma
Corresponding Author: Dr. Rajoo Ramachandran. Postal address - 3A, Anand apartments, JP Avenue, Dr Radhakrishnan salai, Mylapore, Chennai-600004, Tamil Nadu, India.

E-mail: drrajoor.publications@gmail.com

DOI: $10.14260 / \mathrm{jemds} / 2020 / 806$

How to Cite This Article:

Raji VBR, Ramachandran R, Varadaraju PP, et al. 'Roadmap to the land of adrenals': a comprehensive guide to master the radiological diagnosis of adrenal gland lesions. J Evolution Med Dent Sci 2020; 9(48):3676-3682, DOI: $10.14260 / \mathrm{jemds} / 2020 / 806$

Submission 20-08-2020,

Peer Review 13-10-2020,

Acceptance 21-10-2020,

Published 30-11-2020.

Copyright (c) 2020 Venkatesh Bala Raghu Raji et al. This is an open access article distributed under Creative Commons Attribution License [Attribution 4.0 International (CC BY 4.0)] 


\section{BACKGROUND}

Adrenal glands are one of the commonest organs in the body found to have incidentalomas. ${ }^{1,2}$ Majority of the lesions are picked up as incidental findings in abdominal CT and chest CT, which were originally indicated for different reasons. The management of various adrenal lesions varies from completely ignoring them, to assigning the patient to remain on regular follow-up, and to administering definite medical or surgical management. So, it is important to differentiate the benign lesions from the malignant with imaging alone, thereby avoiding unnecessary biopsies. CT is still the most useful modality in imaging the adrenals whilst MR imaging is a useful adjunct in indeterminate cases. In this article, we present an elaborate look at the imaging findings of various adrenal pathologies (Table 1) with due emphasis on contrastenhanced CT appearances encountered in our institution and define the various critical and clinching findings (Table 2 and 3) which aided in the accurate radiological diagnoses.

\section{BENIGN LESIONS}

\section{Adenoma}

Adenomas are the commonest lesions in the adrenal gland, mostly recognized as incidental findings in abdominal CT and chest CT. ${ }^{3}$ It is common enough that an isolated, small sized adrenal lesion in a patient with any known primary malignancy is still an adenoma unless proved otherwise.

Adenomas are well-circumscribed with near-water density ( -5 to $+15 \mathrm{HU}$ ), round to oval in shape, often $<3 \mathrm{~cm}$ in size, seen unilaterally or bilaterally. ${ }^{4}$ Adenomas are benign tumours of adrenal cortical cell origin and contain microscopic fat. Adenomas can be differentiated based on the content of fat and its hormonal activity as lipid-rich / lipid-poor adenomas and hyper-functioning / non-hyper-functioning adenomas respectively. Lipid-rich adrenal adenomas $(<+10 \mathrm{HU})$ are one of the easiest lesions to diagnose with $100 \%$ specificity. However, lipid-poor adenoma $(+10$ to $+30 \mathrm{HU})$ has a precontrast attenuation similar to metastases and thus poses a diagnostic dilemma.5,6 Radiologists resort to contrastenhanced CT study to solve this, in view of adenoma having characteristic contrast excretion / washout pattern.

"Washout" is a term that describes the property of the lesion to return to near baseline attenuation quickly after administering the intra-venous contrast. Adenomas characteristically exhibit rapid washout, which can be defined in the following two ways: an absolute percentage washout (APW) of more than $60 \%$ and a relative percentage washout (RPW) of more than $40 \%$ on 15 -min delayed images. ${ }^{7}$ This method of diagnosing an adenoma has a specificity of near 100 $\% .^{3}$ In general terms, more the washout of an adrenal lesion, more the likelihood of it being benign. In MR imaging, loss of signal in opposed phase chemical shift MR image is the clinching feature of adrenal adenoma. ${ }^{8}$

\section{Note}

APW $=100 \times[($ venous HU - delayed HU) / (venous HU - precontrast $\mathrm{HU})]$;

RPW = 100 [(venous HU - delayed HU) / (venous HU)]

\section{Myelolipoma}

An adrenal myelolipoma is an uncommon benign incidentaloma. Histologically, it is made of mature adipose tissue (lipoid component) admixed with haematopoietic elements (myeloid component).3,4,9 In contrast to adenomas being made of microscopic fat, adrenal myelolipomas contain "macroscopic" fat and can be readily demonstrable in unenhanced CT as a lesion of low attenuation.

Typical unenhanced CT findings of myelolipoma includes a unilateral, well-circumscribed, heterogeneous, fat density lesion of size $2-10 \mathrm{~cm}$. Around $20 \%$ of myelolipomas demonstrate punctate calcifications. On contrast administration, it shows heterogeneous enhancement (myeloid component enhances promptly, while the lipoid tissue does not). ${ }^{4}$ Secondary necrosis and haemorrhage are rare complications.

In MR imaging, a myelolipoma appears as T1 hyper intense and gets suppressed in fat suppression sequences, owing to its adipose component. Lipoma and liposarcoma are the closest differentials. While most myelolipomas are readily diagnosable, difficulty arises when a large retroperitoneal liposarcoma involving the perirenal space and displacing the kidney inferiorly simulates a giant myelolipoma.

Collision tumours are clinical entities wherein two histologically distinct tumour types are identified in the same tumour. ${ }^{10}$ an adenoma-myelolipoma collision tumour is a peculiar collision tumour in adrenals, where a hyperfunctioning fat density lesion can also be seen.

\section{Adrenal Cyst}

Adrenal cysts are quite uncommon lesions. Their size can vary from sub-centimetre to giant lesions which measure up to 20 $\mathrm{cm} .{ }^{11}$ Adrenal cysts can be classified into four types namely: endothelial, epithelial, pseudo and parasitic cysts. In clinical practice, radiologists more often come across pseudocysts, especially in the setting of previous episodes of pancreatitis or trauma. Pseudocysts are lined only by a thin fibrous wall with absent endo or epithelial lining cells. They are postulated to originate from foci of the previous bleed. ${ }^{12}$

In the absence of haemorrhagic complications, adrenal cysts possess near water density in unenhanced CT with HU of 0 to $+10 .^{3}$ Evidence of calcification and septation may or may not be present. Nil enhancement is observed on contrast administration, which is an important feature to differentiate a small cyst from an adenoma. 3, 4, 12 MR features include T1 hypo intensity and T2 hyper intensity. The presence of haemorrhage can alter this, as haemorrhagic cysts exhibit T1 hyper intensity. ${ }^{3,8}$ Superadded infection and haemorrhage are the most common complications of the adrenal cysts.

Adrenal cysts, unlike adenoma, are often surgically managed to treat the symptoms and also to prevent the complications ${ }^{12}$

\section{Adrenal Abscess}

Infected cysts become abscesses and more frequently occur in immuno-compromised patients. Tuberculosis is the most common infectious agent incriminated in secondary adrenalitis. It is the major cause of secondary adrenal insufficiency as it progressively destroys the gland if left untreated. Acute infection results in bilaterally enlarged 
adrenals while a chronic tuberculosis infection might result in shrunken, fibrosed and calcified adrenals.

In contrast-enhanced CT, tuberculosis adrenalitis shows bilateral bulky adrenals with adjacent fat stranding. Enhancing peripheral rim of tissue with central necrosis is commonly seen in cases of frank tubercular abscess. Due to similar imaging features, adrenal tuberculosis can sometimes be confused with lymphoma; however, the presence of lymphomatous involvement in other regions of the body tilts the diagnosis towards secondary lymphoma. Many fungal infections also notably mimic adrenal tuberculosis.

Melioidosis is another systemic infection with an alarmingly rising incidence in the developing countries. ${ }^{13}$ More common in the diabetics, this infectious agent has the propensity to cause abscesses in multiple organs like the spleen, liver, prostate, adrenal, etc.

\section{Ganglioneuroma}

Ganglioneuroma is a benign neoplasm of the young, which arises from the paravertebral sympathetic ganglia and rarely from the neural crest cells of the adrenal medulla. ${ }^{3,14} \mathrm{~A}$ vast majority of ganglioneuromas are hormonally silent and are asymptomatic. When they are symptomatic, they present as vascular / visceral compression syndromes owing to the sheer size of these tumours.

In contrast-enhanced CT, they present as a well-defined homogenous mass of near muscle density, with discrete specks of calcification and delayed and progressive contrast uptake. ${ }^{14,15}$ Vascular compression syndromes can manifest in the form of mild luminal narrowing and frank thrombus formation is extremely rare.

Ganglioneuromas are T1 hypointense and T2 heterogeneous in MRI. This level of T2 heterogeneity can vary depending on the histology of individual tumours. Ganglioneuromas become brighter with increasing myxoid portions (which is T2 hyperintense) and decreasing portions of calcifications (T2 hypointense). ${ }^{3,14}$, and 15

The most common differential diagnosis in children is neuroblastoma which forms the malignant counterpart of ganglioneuroma. It is metabolically active as evident by the increased urinary metabolite levels. Neuroblastoma also shows increased uptake in MIBG studies. ${ }^{16}$

\section{Adrenal Haemorrhage}

Adrenal haemorrhage (adrenal apoplexy) can be classified as traumatic and non-traumatic. Adrenal is often involved in the abdominal trauma of high severity as it is usually unaffected in low-grade trauma. ${ }^{17}$ Neonatal causes of adrenal haemorrhage include stress, prolonged labour, meningococcal septicaemia, etc.3,17 Although most adrenal haemorrhages are asymptomatic, bilateral acute adrenal haemorrhage might result in acute adrenal insufficiency. It is important to know adrenal haemorrhage also presents as secondary changes in lesions like adenomas.

CT appearance of haemorrhage varies from a high-density haematoma (+ 50 to $+90 \mathrm{HU})$ in acute cases to a water density collection in resolved cases.3,18 The adreniform shape of the gland is maintained in most instances. Periadrenal fat stranding is a consistent associated finding.
MRI appearances of adrenal haemorrhage vary depending on the age of the blood clot. Blooming is evident in gradientecho sequences. ${ }^{4,17}$

\section{Infarct}

Adrenal infarct mostly presents itself as an unforeseen complication of antiphospholipid antibody syndrome (APLA). Infarcts can be both haemorrhagic and non-haemorrhagic and are often due to adrenal vein thrombosis rather due to an arterial cause. ${ }^{19}$

Bulky, hypo dense, non-enhancing adrenal gland with adjacent fat stranding are the typical contrast-enhanced CT features of an adrenal infarct. ${ }^{20}$ The T2W MR sequence with added fat suppression provides the maximum yield in the diagnosis. ${ }^{21}$

\section{MALIGNANT LESIONS}

\section{Phaeochromocytoma}

Although a multidisciplinary approach is needed at every turn of radiology, its significance cannot be much emphasized when it comes to diagnosing this master mimicker. A thorough clinical history, laboratory / metabolic workup and imaging assessment with multiple modalities are needed and should be correlated to arrive at a precise diagnosis of phaeochromocytoma ( $10 \%$ malignant). ${ }^{22}$

Phaeochromocytoma is a rare catecholamine-secreting tumour of adrenal medulla, arising from the chromaffin cells of neural crest cell origin. Its extra-adrenal counterpart is called paraganglioma arising from the sympathetic and parasympathetic ganglia. ${ }^{3,4,22 \text {, and } 23}$

Although pheochromocytoma is best known for its variegated imaging appearances, it typically presents as a unilateral, well-circumscribed, encapsulated solid tumour of size $>3 \mathrm{~cm} .{ }^{24}$ In unenhanced CT, it can appear homogenous (muscle density attenuation) or heterogeneous, due to the presence of calcifications (10\%), cystic, necrotic or haemorrhagic areas. On contrast administration, pheochromocytomas are hyper vascular with brisk and avid uptake. Heterogeneous enhancement is noted in the lesions with interspersed areas of cysts or necrosis. The washout properties of pheochromocytoma are quite variable. ${ }^{23}$

Phaeochromocytoma is $\mathrm{T} 1$ isointense to muscle and T2 hyperintense. The classic "light bulb sign" in T2WI is variably seen (range: $11 \%$ to $65 \%$ ). ${ }^{9,25}$ The iodine-123 metaiodobenzylguanidine (MIBG) scan is indicated routinely for ectopic, recurrent and metastatic pheochromocytomas. An increased uptake is noted in metabolically active lesions.

The wide-ranging appearance of pheochromocytoma in CT has posed great diagnostic predicaments. Phaeochromocytoma may sometimes mimic a large adenoma with increased contrast washout.4,25 Although evidence of macroscopic fat in an adrenal lesion places the working diagnosis more towards myelolipoma, pheochromocytoma can sometimes notoriously manifest itself with foci of macroscopic fat. Hence a meticulous multi-modality approach with comprehensive metabolic workup (24 hours plasma metanephrine levels, etc.) is vital in obviating unnecessary biopsies. 


\begin{tabular}{|c|c|c|}
\hline Sl. no. & Adrenal Lesion & Typical Imaging Characteristics *† \\
\hline 1 & Adenoma & Small, well-circumscribed, less than $+10 \mathrm{HU}$, rapid washout post-contrast, loss of signal on opposed phase MR imaging (microscopic fat). \\
\hline 2 & Myelolipoma & $\begin{array}{c}\text { Unilateral, well-circumscribed, fat density lesion, heterogeneous enhancement, delayed washout post-contrast, suppressed on fat suppression MR } \\
\text { sequences (macroscopic fat). }\end{array}$ \\
\hline 3 & Cyst & Small to large, well-circumscribed, near water density lesion, evidence of calcification, septation or haemorrhage, nil enhancement post-contrast. \\
\hline 4 & $\begin{array}{c}\text { Abscess } \\
\text { (Tuberculosis) }\end{array}$ & $\begin{array}{l}\text { Acute: Bulky adrenal with adjacent fat stranding, central hypodense collection, peripheral rim of enhancing tissue. } \\
\text { Chronic: Shrunken fibrosed adrenal with or without calcification. }\end{array}$ \\
\hline 5 & Ganglioneuroma & $\begin{array}{l}\text { Large well-defined mass of muscle density with stippled calcification, related to abdominal vessels but without evidence of invasion / thrombosis, } \\
\text { delayed and progressive enhancement post-contrast. }\end{array}$ \\
\hline 6 & Haemorrhage & $\begin{array}{l}\text { Normal shaped adrenal with peripheral fat stranding, hyperdense }(+50 \text { to }+90 \mathrm{HU}) \text { cystic collection on unenhanced CT with nil enhancement post- } \\
\text { contrast, blooming on MR gradient sequences. }\end{array}$ \\
\hline 7 & Infarct & Bulky adrenal with fat stranding, hypodense on unenhanced CT with nil enhancement post-contrast. \\
\hline 8 & $\begin{array}{l}\text { Phaeochromocytoma } \\
\quad \neq\end{array}$ & $\begin{array}{l}\text { Hypervascular heterogeneous muscle density lesion with cystic, necrotic or haemorrhagic areas, with brisk contrast uptake and variable washout } \\
\text { properties, light bulb sigh on T2W MRI. }\end{array}$ \\
\hline 9 & $\begin{array}{c}\text { Adrenocortical } \\
\text { carcinoma } \neq\end{array}$ & $\begin{array}{l}\text { Ill-defined large, unilateral heterogeneous mass with cystic, necrotic or haemorrhagic areas, delayed washout post-contrast, mass effect and invasion } \\
\text { to adjacent viscera and vessels. }\end{array}$ \\
\hline 10 & Lymphoma & $\begin{array}{l}\text { Ill-defined discrete large sized hypovascular lesion of muscle density with evidence of retroperitoneal involvement, heterogeneous and progressive } \\
\text { enhancement with delayed washout, increased FDG uptake on PET. }\end{array}$ \\
\hline 11 & Metastasis ‡ & $\begin{array}{l}\text { Bilateral large, discrete or diffuse solid heterogeneous soft tissue density lesion with irregular and invasive margins and areas of cysts, necrosis or } \\
\text { haemorrhage, evidence of primary elsewhere, increased FDG uptake on PET. }\end{array}$ \\
\hline 12 & $\begin{array}{l}\text { Ganglioneuroblastoma } \\
\text { and Neuroblastomas }\end{array}$ & $\begin{array}{l}\text { Ill-defined lobulated inhomogeneous soft tissue mass of with areas of coarse / stippled calcification and with little or nil contrast enhancement, } \\
\text { pediatric age group, evidence of abdominal vessel encasement and intraspinal extension. }\end{array}$ \\
\hline & & Table 1. Image Interpretation Pearls - Typical Imaging Characteristics of Adrenal Lesions \\
\hline
\end{tabular}

\begin{tabular}{|c|c|c|c|c|c|c|}
\hline $\begin{array}{l}\text { Sl. } \\
\text { No. }\end{array}$ & $\begin{array}{l}\text { Adrenal } \\
\text { Lesion }\end{array}$ & Texture & $\begin{array}{c}\text { Density on Unenhanced } \\
\text { CT }\end{array}$ & $\begin{array}{l}\text { Post-Contrast } \\
\text { characteristics* }\end{array}$ & $\begin{array}{l}\text { Clinical } \\
\text { Workup }\end{array}$ & Malignant Potential \\
\hline 1 & Adenoma & Homogeneous & $\begin{array}{c}<+10 \mathrm{HU} \\
(<+30 \mathrm{HU} \text { in lipid-poor type })\end{array}$ & Rapid washout & Nil & Benign \\
\hline 2 & Myelolipoma & Heterogeneous & Fat density & Delayed washout & Nil & Benign \\
\hline 3 & Cyst & $\begin{array}{c}\text { Heterogeneous } \\
\text { (haemorrhage or necrosis) }\end{array}$ & Near water density & Nil enhancement & Nil & $\begin{array}{c}\text { Benign } \\
\text { (Very Rarely Turns } \\
\text { Malignant) }\end{array}$ \\
\hline 4 & Abscess & Heterogeneous (central necrosis) & Hypodense $(<+30)$ & Peripheral enhancement & Raised WBC counts & Benign \\
\hline 5 & Ganglioneuroma & Heterogeneous (calcification) & $<+40 \mathrm{HU}$ & $\begin{array}{c}\text { Delayed and progressive } \\
\text { enhancement }\end{array}$ & Nil & Benign \\
\hline 6 & Haemorrhage & Homogeneous & +50 to $+90 \mathrm{HU}$ & Nil enhancement & Serum cortisol level & Benign \\
\hline 7 & Infarct & Homogeneous & Hypodense $(<+30)$ & Nil enhancement & Serum cortisol level & Benign \\
\hline 8 & Phaeochromocytoma & $\begin{array}{c}\text { Heterogeneous } \\
\text { (cyst, haemorrhage or necrosis) }\end{array}$ & +10 to $+40 \mathrm{HU}$ & $\begin{array}{l}\text { Brisk enhancement with } \\
\text { variable washout }\end{array}$ & $\begin{array}{l}\text { Serum and urine } \\
\text { metabolite level }\end{array}$ & $90 \%$ Benign \\
\hline 9 & Adrenocortical carcinoma & $\begin{array}{c}\text { Heterogeneous } \\
\text { (cyst, haemorrhage or necrosis) }\end{array}$ & +10 to $+40 \mathrm{HU}$ & Delayed washout & $\begin{array}{l}\text { Serum hormonal } \\
\text { level }\end{array}$ & Malignant \\
\hline 10 & Lymphoma & $\begin{array}{c}\text { Heterogeneous } \\
\text { (calcifications or necrosis) }\end{array}$ & +10 to $+40 \mathrm{HU}$ & $\begin{array}{l}\text { Hypo vascular with } \\
\text { delayed washout }\end{array}$ & Tumour marker & Malignant \\
\hline 11 & Metastasis & $\begin{array}{c}\text { Heterogeneous } \\
\text { (cyst, haemorrhage or necrosis) }\end{array}$ & +10 to $+40 \mathrm{HU}$ & Delayed washout & Tumour marker & Malignant \\
\hline 12 & $\begin{array}{l}\text { Ganglioneuroblastoma } \\
\text { and Neuroblastomas }\end{array}$ & $\begin{array}{l}\text { Heterogeneous } \\
\text { (calcification, haemorrhage or necrosis) }\end{array}$ & +10 to $+40 \mathrm{HU}$ & $\begin{array}{c}\text { Little or nil contrast } \\
\text { enhancement }\end{array}$ & $\begin{array}{l}\text { Serum and urine } \\
\text { metabolite level }\end{array}$ & Malignant \\
\hline
\end{tabular}

\begin{tabular}{|c|c|c|c|}
\hline Sl. No. & Adrenal Lesion & Closest Differential & Differentiating Features \\
\hline 1 & Myelolipoma & Liposarcoma & Suprarenal location of myelolipoma and retroperitoneal location of liposarcoma \\
\hline 2 & Ganglioneuroma & Ganglioneuroblastoma and Neuroblastomas & Benign nature, metabolically inactive, decreased uptake in MIBG studies \\
\hline 3 & Phaeochromocytoma & Large adenoma, large myelolipoma. & Hypervascularity, washout properties, T2 light bulb sign and metabolic workup \\
\hline 4 & Adrenocortical carcinoma & Large lipid-poor adenoma, pheochromocytoma & $\begin{array}{l}\text { Large size and heterogeneity, hypovascualrity, hormonal activity present and nil metabolic } \\
\text { activity. }\end{array}$ \\
\hline 5 & Metastasis & Lipid-poor adenoma & Invasive margins, presence of primary elsewhere, increased FDG uptake, delayed washout. \\
\hline \multicolumn{4}{|c|}{ Table 3. Image Interpretation Pearls - Closest Differential of Various Adrenal Lesions along with Clinching Features which Help Their Differentiation } \\
\hline
\end{tabular}

\section{Adrenocortical Carcinoma}

Adrenocortical carcinoma (ACC) is a rare tumour of adrenal cortical origin with composite imaging appearances and clinical presentations (like pheochromocytomas). It has a bimodal peak, less than 10 years and later 40 - 50 years with 1.5:1 female preponderance. ${ }^{7}$ It has many syndromic associations namely Li-Fraumeni syndrome, BeckwithWiedemann Syndrome, Carney triad and MEN-I syndrome. ${ }^{26}$ Around one-half of these tumours are hormonally active and unlike an adenoma, an ACC secretes multiple hormones like cortisol, aldosterone, androgen, and oestrogen. 
ACCs can grow to large sizes and greatly displace the adjacent viscera. Typical presentation involves a unilateral large, heterogeneous mass (before and after contrast administration), with invasive tumour margins and areas of necrosis, haemorrhage and / or calcifications within. It typically has a delayed contrast washout.

ACCs appear T1 hypo and T2 hyper intense in MRI; however, haemorrhagic areas appear T1 hyper intense. ACCs are known to invade the adjacent vessels, especially the inferior vena cava. MRI is superior to CT in detecting and assessing the extent of vascular invasion and tumour thrombus. ${ }^{27}$

Owing to its inconstant imaging characteristics, many adrenal lesions mimic ACC. However, the sheer size and heterogeneity of the mass should tilt the working diagnosis towards ACC. When small, ACC mimics lipid-poor adenoma and can be differentiated from it by its washout properties. ${ }^{28}$ Like ACC, pheochromocytoma also appears heterogeneous. However, the latter is usually hyper vascular with variable washout properties. The lab work-up also can solve this predicament.

\section{Lymphoma}

Adrenal lymphoma can be arising primarily from within the adrenal gland or as a result of the secondary involvement of surrounding lymph nodes. ${ }^{29}$ Primary adrenal lymphoma (PAL) is a rare tumour which occurs predominantly in the elderly. They often present bilaterally (70 \%) as discrete masses without any extra-adrenal lymph node involvement. ${ }^{30}$ Secondary involvement of the adrenal glands is most often a reflection of multicentric disease, especially with the involvement of ipsilateral kidney and the retroperitoneal lymph nodes. ${ }^{31}$ Lymphoma can rarely result in adrenal insufficiency (especially in PAL, following the destruction of the gland).

Typical unenhanced CT appearance involves a discrete large sized heterogeneous muscle density mass lesion. Evidence of retroperitoneal involvement can be seen in secondary causes. On contrast administration, lymphomas are hypovascular (unlike most malignant adrenal lesions) and show heterogeneous and progressive enhancement with delayed washout. $^{32}$ Like metastases, lymphomas have nonspecific MRI findings (T1 hypointense and T2 hyper intense to muscles). ${ }^{33}$ The incidence of PAL is so low that, visualization of isolated bilateral masses of the adrenals could most likely be due to metastases than a PAL. ${ }^{34}$

\section{Metastasis}

The adrenal is the fourth commonest organ to get metastasized next to the liver, lung and the bone.3,4 Major causes include lymphoma and carcinoma of lung (up to $40 \%$ ) while the minor causes include melanoma, carcinoma breast, prostate, stomach and colorectal carcinoma. ${ }^{35}$

The typical CT presentation involves bilateral $(\sim 50 \%)$, large, discrete or diffuse, solid, heterogeneous, soft tissue density lesion with irregular and invasive margin. Heterogeneous enhancement (post-contrast) is due to the presence of haemorrhage, necrosis or calcifications.
Characteristically, adrenal metastases demonstrate a prolonged enhancement and delayed washout. 36

Metastases appear as T2 hyperintense and do not show signal drop on the opposed-phase images of chemical-shift MRI. ${ }^{4}$ PET-CT has a definite role (sensitivity $97 \%$, specificity $91 \%$ ) showing increased FDG uptake.3,37

In case of any known primary elsewhere, the presence of interval change (especially in size) in comparison with previous images is an important feature which dramatically increases the likelihood of the adrenal lesion being a metastasis. Small metastasis can resemble lipid-poor adenoma because of similar attenuation ( $>10 \mathrm{HU}$ ). However, they can be differentiated by their washout properties. Metastases of hepatocellular carcinoma and renal cell carcinoma are hyper vascular and may mimic pheochromocytoma. ${ }^{36}$ However, the latter can be diagnosed with the aid of patient's clinical history and metabolic workup.

\section{Ganglioneuroblastoma and Neuroblastoma}

Adrenal ganglioneuroblastoma (GNB) and neuroblastoma (NB) are the intermediate and malignant counterparts of the benign tumour, ganglioneuroma. Both these pediatric adrenal tumours possess malignant potential (NB $>>$ GNB) and have similar imaging appearances (i.e., they are discriminated purely on the basis of histopathology). Neuroblastomas are made of primitive neuroblasts whereas, ganglioneuroblastomas consist of a mixture of mature ganglion cells and neuroblast cells. ${ }^{37}$

CT appearances vary depending on the cell type of each tumour and the number of mature elements. Typical CT presentation involves an ill-defined lobulated inhomogeneous soft tissue mass of suprarenal region with areas of calcification, with or without areas of necrosis and haemorrhage with little or nil contrast enhancement. ${ }^{38}$ Abdominal vessel encasement is classically present. MR is the imaging modality of choice to assess the intraspinal extension of the primary adrenal tumour. GNB and NB are T1 hypo- and T2 hyper intense on MRI.

The closest differential of GNB and NB is Wilm's tumour. The presence of coarse / amorphous / stippled calcifications can differentiate them from Wilm's tumour. ${ }^{39}$

\section{CONCLUSIONS}

With increased use of cross-sectional imaging in patients with various unrelated abdominal and thoracic ailments, the incidence of adrenal incidentalomas being picked up is on the rise. The unenhanced CT appearance and the washout properties post-contrast are the two most indispensable features in arriving at a diagnosis of most adrenal lesions. In this article, we have discussed the various pivotal imaging findings (with much emphasis on contrast-enhanced CT modality), which aid the radiologists to efficiently arrive at the single best diagnosis. In this manner, the radiologists can help limit the number of adrenal biopsies in order to characterize the indeterminate lesions and thereby improve the patient care. 


\section{List of Abbreviations}

CT - Computed Tomography; HU - Hounsfield Unit; APWAbsolute Percentage Washout; RPW - Relative Percentage Washout; MRI - Magnetic Resonance Imaging; APLA Antiphospholipid Antibody Syndrome; MIBG- Iodine-123 Meta-Iodobenzylguanidine; ACC - Adrenocortical Carcinoma; MEN - Multiple Endocrine Neoplasia; PAL - Primary Adrenal Lymphoma; GNB - Ganglioneuroblastoma; NB Neuroblastoma.

Financial or other competing interests: None.

Disclosure forms provided by the authors are available with the full text of this article at jemds.com.

\section{REFERENCES}

[1] Boland GWL. Adrenal imaging: why, when, what, and how? Part 1. Why and when to image? AJR Am J Roentgenol 2011;196(6):W377-81.

[2] Sandrasegaran K, Patel AA, Ramaswamy R, et al. Characterization of adrenal masses with diffusionweighted imaging. AJR Am J Roentgenol 2011;197(1):132-8.

[3] Herr K, Muglia VF, Koff WJ, et al. Imaging of the adrenal gland lesions. Radiol Bras 2014;47(4):228-39.

[4] Johnson PT, Horton KM, Fishman EK. Adrenal mass imaging with multidetector CT: pathologic conditions, pearls, and pitfalls. Radiographics 2009;29(5):1333-51.

[5] Caoili EM, Korobkin M, Francis IR, et al. Delayed enhanced CT of lipid-poor adrenal adenomas. AJR Am J Roentgenol 2000;175(5):1411-5.

[6] Caoili EM, Korobkin M, Francis IR, et al. Adrenal masses: characterization with combined unenhanced and delayed enhanced CT. Radiology 2002;222(3):629-33.

[7] Berland LL, Silverman SG, Gore RM, et al. Managing incidental findings on abdominal CT: white paper of the ACR incidental findings committee. J Am Coll Radiol 2010;7(10):754-73.

[8] El-Kalioubie M, Emad-Eldin S, Abdelaziz O. Diffusionweighted MRI in adrenal lesions: a warranted adjunct? Egypt J Radiol Nucl Med 2016;47(2):599-606.

[9] Rao P, Kenney PJ, Wagner BJ, et al. Imaging and pathologic features of myelolipoma. Radiographics 1997;17(6):1373-85.

[10] Murthaiah P, Truskinovsky AM, Shah S, et al. Collision tumour versus multiphenotypic differentiation: a case of carcinoma with features of colonic and lung primary tumours. Anticancer Res 2009;29(5):1495-7.

[11] Abeshouse GA, Goldstein RB, Abeshouse BS. Adrenal cysts: review of the literature and report of three cases. J Urol 1959;81(6):711-9.

[12] Rozenblit A, Morehouse HT, Amis ES. Cystic adrenal lesions: CT features. Radiology 1996;201(2):541-8.

[13] Raji VBR, Vasanthraj PK, Ramachandran R, et al. Multisystem infection - tuberculosis or melioidosis? Egypt J Radiol Nucl Med 2018;49(3):689-92.

[14] Rha SE, Byun JY, Jung SE, et al. Neurogenic tumours in the abdomen: tumour types and imaging characteristics. Radiographics 2003;23(1):29-43.
[15] Ichikawa T, Koyama A, Fujimoto $\mathrm{H}$, et al. Retroperitoneal ganglioneuroma extending across the midline: MR features. Clin Imaging 1993;17(1):19-21.

[16] Gilshtein H, Peled Z, Grunner S, et al. Ganglioneuroma of the adrenal gland: a rare tumour in a rare location. Case Rep Oncol 2012;5(3):487-9.

[17] Taffel M, Haji-Momenian S, Nikolaidis P, et al. Adrenal imaging: a comprehensive review. Radiol Clin North Am 2012;50(2):219-43.

[18] Dunnick NR. Hanson lecture. Adrenal imaging: current status. AJR Am J Roentgenol 1990;154(5):927-36.

[19] Glomski SA, Guenette JP, Landman W, et al. Acute nonhaemorrhagic adrenal infarction in pregnancy: 10year MRI incidence and patient outcomes at a single institution. AJR Am J Roentgenol 2018;210(4):785-91.

[20] Green PAD, Ngai IM, Lee TT, et al. Unilateral adrenal infarction in pregnancy. BMJ Case Rep 2013;2013:bcr2013009997.

[21] Guenette JP, Tatli S. Nonhaemorrhagic adrenal infarction with magnetic resonance imaging features during pregnancy. Obstet Gynecol 2015;126(4):775-8.

[22] Baez JC, Jagannathan JP, Krajewski K, et al. Pheochromocytoma and paraganglioma: imaging characteristics. Cancer Imaging 2012;12(1):153-62.

[23] Elder EE, Elder G, Larsson C. Pheochromocytoma and functional paraganglioma syndrome: no longer the $10 \%$ tumour. J Surg Oncol 2005;89(3):193-201.

[24] Blake MA, Kalra MK, Maher MM, et al. Pheochromocytoma: an imaging chameleon. Radiographics 2004;24 Suppl 1:S87-99.

[25] Leung K, Stamm M, Raja A, et al. Pheochromocytoma: the range of appearances on ultrasound, CT, MRI, and functional imaging. AJR Am J Roentgenol 2013;200(2):370-8.

[26] Libe R, Bertherat J. Molecular genetics of adrenocortical tumours, from familial to sporadic diseases. Eur J Endocrinol 2005;153(4):477-87.

[27] Reznek RH. CT/MRI in staging renal cell carcinoma. Cancer Imaging 2004;4(Spec No A):S25-32.

[28] Schieda N, Siegelman ES. Update on CT and MRI of adrenal nodules. AJR Am J Roentgenol 2017;208(6):1206-17.

[29] Sánchez CDM, Ruiz L, González JL, et al. Acute adrenal insufficiency secondary to bilateral adrenal B-cell lymphoma: a case report and review of the literature. Ecancermedicalscience. 2016;10:634.

[30] Simpson WG, Babbar P, Payne LF. Bilateral primary adrenal non-Hodgkin's lymphoma without adrenal insufficiency. Urol Ann 2015;7(2):259-61.

[31] Glazer HS, Lee JK, Balfe DM, et al. Non-Hodgkin lymphoma: computed tomographic demonstration of unusual extranodal involvement. Radiology 1983;149(1):211-7.

[32] Zhou L, Peng W, Wang C, et al. Primary adrenal lymphoma: radiological; pathological, clinical correlation. Eur J Radiol 2012;81(3):401-5.

[33] Rashidi A, Fisher SI. Primary adrenal lymphoma: a systematic review. Ann Hematol 2013;92(12):1583-93.

[34] Mansmann G, Lau J, Balk E, et al. The clinically inapparent adrenal mass: update in diagnosis and management. Endocr Rev 2004;25(2):309-40. 
[35] Adam SZ, Nikolaidis P, Horowitz JM, et al. Chemical shift MR imaging of the adrenal gland: principles, pitfalls, and applications. Radiographics 2016;36(2):414-32.

[36] Boland GWL, Dwamena BA, Sangwaiya MJ, et al. Characterization of adrenal masses by using fdg pet: a systematic review and meta-analysis of diagnostic test performance. Radiology 2011;259(1):117-26.

[37] Lonergan GJ, Schwab CM, Suarez ES, et al. Neuroblastoma, ganglioneuroblastoma, and ganglioneuroma: radiologic- pathologic correlation. Radiographics 2002;22(4):91134.

[38] Papaioannou G, McHugh K. Neuroblastoma in childhood: review and radiological findings. Cancer Imaging 2005;5(1):116-27.

[39] Li JT, Dai YH, Kuo SM. A massive retroperitoneal neuroblastoma with stenosis of the inferior vena cava in a 5-month-old boy. BMJ Case Rep 2014;2014:bcr2014203904. 